\title{
Soot Volume Fraction MEASUREMENTS \\ in A Three-Dimensional LAMinar DifFUSION FLAME ESTABLISHED IN MICROGRAVITY
}

\author{
GUILLAUME LEGROS ${ }^{(1) \dagger}$, PIERRE JOULAIN ${ }^{(1)}$, \\ JEAN-PIERRE VANTELON ${ }^{(1)}$, DENIS BERTHEAU ${ }^{(2)}$, \\ ANDRES FUENTES ${ }^{(1)}$, and JOSE L. TORERO ${ }^{(3)}$
}

(1) Laboratoire de Combustion et de Détonique

UPR 9028 du CNRS - Poitiers (FRANCE)

(2) Laboratoire de Mécanique et de Physique des Matériaux

UMR $6617 \mathrm{du}$ CNRS - Poitiers (FRANCE)

(3) School of Engineering and Electronics

The University of Edinburgh, Edinburgh (UNITED KINGDOM)

$\dagger$ corresponding author:

Laboratoire de Combustion et de Détonique

1, av. C. Ader

BP 40109

86961 Chasseneuil-Futuroscope Cedex

FRANCE

fax: 0033549498291

email: legros@lcd.ensma.fr 


\section{Abstract}

A methodology for the estimation of the soot volume fraction in a three-dimensional laminar diffusion flame is presented. All experiments are conducted in microgravity and have as objective producing quantitative data that can serve to estimate radiative heat transfer in flames representative of fires in spacecraft. The competitive nature of formation and oxidation of soot and its direct coupling with the streamlines (source of oxygen) require for these measurements to be conducted within the exact configuration. Thus three-dimensional measurements are needed. Ethylene is injected through a square porous burner and the oxidizer flows parallel to its surface. The methodology uses $\mathrm{CH}^{*}$ chemiluminescence measurements to correct for three-dimensional effects affecting light attenuation measurements. Corrected local soot concentrations are thus obtained. All experiments are conducted during parabolic flights and the parameters varied are fuel and oxidizer flow rates.

\section{Keywords}

diffusion flame

soot

microgravity

fire safety

\section{Shortened title}

Sooting quantification in a non-buoyant laminar diffusion flame 


\section{Nomenclature}

\section{General symbols}

\begin{tabular}{|c|c|c|}
\hline$a_{\lambda}$ & spectral absorption coefficient & $\mathrm{m}^{-1}$ \\
\hline$A_{\lambda}$ & spectral extinction factor as defined by eq (3) & - \\
\hline$D$ & soot particle diameter & $\mathrm{nm}$ \\
\hline$f_{\text {soot }}$ & soot volume fraction & ppm \\
\hline$g_{0}$ & ground gravity level & $9.8 \mathrm{~m} . \mathrm{s}^{-2}$ \\
\hline height $t_{z}$ & integration pathway along the $z$ axis & $\mathrm{mm}$ \\
\hline$i_{\lambda}$ & spectral light intensity & arbitrary unit \\
\hline$I$ & light intensity & arbitrary unit \\
\hline$k_{\lambda}$ & spectral extinction coefficient & $\mathrm{m}^{-1}$ \\
\hline$L$ & light pathway length & $\mathrm{m}$ \\
\hline $\operatorname{Max}_{y}$ & maximum value of a curve $S(y)$ & - \\
\hline $\operatorname{Max}_{z}$ & maximum value of a curve $S(z)$ & - \\
\hline$n_{\lambda}$ & real part of the refractive index at the wavelength $\lambda$ & - \\
\hline$S$ & signal given by a CCD pixel & arbitrary unit \\
\hline$t_{\text {sampling }}$ & soot sampling duration in the flame & $\mathrm{s}$ \\
\hline$V_{F}$ & fuel injection velocity & $\mathrm{mm} \cdot \mathrm{s}^{-1}$ \\
\hline$V_{o x}$ & oxidizing blowing velocity & $\mathrm{mm} \cdot \mathrm{s}^{-1}$ \\
\hline$w_{i d t h}$ & integration pathway along the & $\mathrm{mm}$ \\
\hline
\end{tabular}




$\begin{array}{llc}x & \text { streamwise coordinate } & \mathrm{mm} \\ y & \text { transverse coordinate } & \mathrm{mm} \\ z & \text { vertical coordinate } & \mathrm{mm} \\ z_{\max } & \text { location along the } z \text {-axis where } a_{\lambda}(z) \text { is maximum } & \mathrm{mm}\end{array}$

\section{Greek symbols}

$\alpha \quad$ constant ratio as defined by eq (9)

$\Delta y \quad$ width at half the height of a curve $\mathrm{S}(\mathrm{y}) \quad \mathrm{mm}$

$\Delta z \quad$ width at half the height of a curve $\mathrm{S}(\mathrm{z}) \quad \mathrm{mm}$

$\Delta z_{C} \quad$ corrective component for $\Delta z \quad \mathrm{~mm}$

$\eta \quad$ optics efficiency

$\kappa_{\lambda} \quad$ imaginary part of the refractive index at the wavelength $\lambda-$

$\begin{array}{lll}\lambda & \text { wavelength } & \mathrm{nm}\end{array}$

$\dot{\omega} \quad$ volumetric rate of heat release $\quad W . \mathrm{m}^{-3}$

$\Omega \quad$ solid angle of view $\quad$ sr

\section{Subscripts}

side measurement from the side

top measurement from the top

$\lambda \quad$ spectral value

corr corrected value 


\section{Introduction}

In microgravity, due to the absence of natural convection, time scales associated with combustion processes are much longer and radiation can be the predominant mode of heat transfer even for small diffusion flames (Olson and T'ien, 2000). Soot production is enhanced with increasing residence times, further emphasizing the role of radiation (Megaridis et al., 1996). Thus, a better understanding of soot formation and radiative emissions for microgravity diffusion flames is of extreme importance to many practical combustion related processes such as spacecraft fire safety (Olson and T'ien, 2000; Fernandez-Pello et al., 2000; Torero et al., 2002).

Several studies have attempted to describe sooting behavior of non-buoyant diffusion flames, notable are the studies by Faeth and coworkers (Lin et al., 1999; Lin and Faeth, 1999; Xu et al., 2002) and Konsur and coworkers (Megaridis et al., 1996; Konsur et al., 1999a,b). Underpinning these studies is the smoke point concept and the possibility of inferring the flame radiative losses only from the oxidizer and fuel flow rates. This concept was originally proposed by Markstein and De Ris, for normal gravity flames (Markstein and De Ris, 1984) and establishes that the flame quenches due to radiative heat losses at a fixed soot concentration. Flames can therefore be "closed-tip", if fuel is consumed before this critical concentration is attained, and "open-tip" when quenching occurs before total fuel consumption. Flame lengths, and consequently co-current flame spread, can then be linked to the critical soot concentration. Markstein and De Ris (1984) empirically verified this concept and alluded to the possibility of using the smoke point as a material flammability criterion. 
Despite the utility of this approach, the question that remains unanswered is how the critical soot concentration for flame quenching is attained. Furthermore, for "open-tip" flames, the flame length can only be determined if soot concentrations can be tracked along the reactive zone. Prediction of other relevant parameters, such as flame geometry, also requires the definition of the flame length therefore can only be determined for "closed-tip" flames or if local soot concentrations are available. Significant disagreement between experiments and predictions is evident for "open-tip" flames (Lin et al., 1999; Lin and Faeth, 1999; Xu et al., 2002).

Soot concentrations are the result of two competitive processes, soot formation and oxidation. Both processes are influenced by the oxygen concentration therefore local soot concentrations depend on the structure of the flow field in the proximity of the flame. Smoke point studies conducted with axisymmetric jet flames showed that this dependency can be modified by the experimental set-up (Sunderland et al., 1994; Urban et al., 2000) or the global residence time (Megaridis et al., 1996; Konsur et al., 1999b). Konsur et al. highlighted that the peak soot volume fraction decreased when reducing the characteristic flow residence time. Finally Mortazavi et al. (1993) demonstrated the capability to alter soot characteristic residence times in non-buoyant laminar jet diffusion flames by varying the characteristic velocities.

Using a boundary layer geometry, Vietoris et al. (2000) and Brahmi et al. (1998) showed that the luminosity of a diffusion flame established in microgravity increased with the oxidizer velocity for both solid (Vietoris et al., 2000) and gaseous (Brahmi et al., 1998) fuels. A subsequent numerical study proved that the orientation of the flow streamlines seems to be 
at the origin of the changes in luminous intensity (Rouvreau et al., 2002). Since luminous intensity can be correlated to soot oxidation, these observations provide indirect evidence of the importance of the flow field on the outcome of the soot formation/oxidation competition. Furthermore, they imply that global residence times are not sufficient and that soot measurements cannot be directly extrapolated between different configurations.

Past studies have shown the importance of the flow field on the ultimate soot volume fraction. Nevertheless, understanding of the different processes remains incomplete, and modelling of soot production for a three-dimensional diffusion flame is still not possible. Furthermore, there are currently no experimental measurements that explore this aspect of the problem and that can be used for direct validation of models. The present study aims to provide detailed microgravity soot volume fraction and emission measurements on a threedimensional flame. Ethylene is injected across a porous burner and the oxidizer flows parallel to the surface. The flames for this particular configuration are not axisymmetric, thus, classical de-convolution techniques cannot be used. Extrapolation from two-dimensional studies is not possible because the fuel injection and flame induced thermal expansion which results in three-dimensional flow patterns that cannot be described using simple analytical solutions (Brahmi et al., 1998; Vietoris et al., 2000).

Extinction measurements require an unobstructed path therefore data can only be collected from a limited number of directions. In contrast, $\mathrm{CH}^{*}$ chemiluminescence measurements can be conducted from multiple directions, and therefore can be used to correct the light attenuation measurements. The correction allows to infer local soot concentrations and to explore in a systematic manner the effect of fuel and oxidizer velocity. Finally, these measu- 
rements will provide soot volume fraction necessary to model radiative heat transfer for the specific flames reported by Brahmi et al. (1998) and Vietoris et al. (2000).

\section{Description of the experimental set up}

Figure 1 represents a schematic of the experimental set-up. A close-up is provided of the gas burner. The relevant dimensions are defined in Figure 1. Fuel is injected through a square sintered bronze porous burner, which has a 50x50 $\mathrm{mm}^{2}$ effective section of injection. The oxidizer flow is introduced through several settling chambers and through honeycomb plates to guarantee a laminar flow. Mass flow controllers from BROOKS corp. were controlled through a data acquisition and command board.

The diffusion flame is established inside a 50 litre stainless steel combustion chamber. Confinement is required in microgravity facilities for safety reasons. The effect of confinement on the flow has been studied before showing that the volume of the chamber is sufficient to keep the flame free from wall effects. The pressure is kept at atmospheric values by means of a controlled mass flow meter placed at the exhaust of the duct. The combustion chamber has three large quartz windows for optical access.

Ethylene was chosen as a fuel because of its particular sooting behavior. The large amount of soot present simplified the measurements and thus the validation of the technique. The oxidizer corresponds to a mixture of $35 \% \mathrm{O}_{2}$ and $65 \% \mathrm{~N}_{2}$. This mixture was chosen since an increased $\mathrm{O}_{2}$ partial pressure emphasizes both sooting behavior and $\mathrm{CH}^{*}$ spontaneous emission levels.

Two Sony CCD cameras, providing 8-bit black and white measurements on 720x480 pixels 
matrix, were installed (see FIG. 1): one above the burner, the other on the side. The cameras were mounted with narrow band filters centred at $\lambda=431 \mathrm{~nm}$ and whose bandwidth at half the transmissivity maximum were of $10 \mathrm{~nm}$. Both cameras were used to record $\mathrm{CH}^{*}$ emission (at $\lambda=431 \mathrm{~nm}$ ). A beam splitter was used to separate the light collected through the side view into two cameras. Approximately $40 \%$ (measured at $532 \mathrm{~nm}$ ) of the light went through the splitter and into the side camera mounted with a $431 \mathrm{~nm}$ filter. The remaining of the visible light was reflected towards a third Sony CCD camera of similar characteristics. This third had a narrow band filter centred at $\lambda=532 \mathrm{~nm}$ and whose bandwidth at half the transmissivity maximum was also of $10 \mathrm{~nm}$. This camera performed light attenuation measurements at $532 \mathrm{~nm}$. The $532 \mathrm{~nm}$ filter was chosen to record the emission of a $100 \mathrm{~mW}$ green laser diode $(\lambda=532 \mathrm{~nm})$ which emitted light that crossed the flame in the $y$ direction (see FIG. 1). The light is then partially absorbed when crossing the flame. This wavelength was chosen as a good compromise: at this wavelength, the flame exhibits low spectral emission levels and scattering can still be neglected (see criterion (5) below). The diode was located far enough from the burner to use its natural divergence to backlight the investigated area. A slow chopper was used to block the laser diode emission. Using the chopper, 10 backlit images, followed by 10 unbacklit ones, were recorded. All images were synchronized using visible signals. Further details of the experimental procedures can be found in reference (Legros, 2003).

The zone of interest was immediately above the burner, thus the backlighting was centred at this location so that the light beams could be considered parallel and coming straight to the camera lens within this zone. Based on simple geometric considerations, it can be 
inferred that using uncollimated rays leads to an error margin lower than $0.2 \%$, which can be considered negligible, especially when compared to the error induced by the filter, due to the fact that it is not exactly spectral. Intensity uniformity of the backlighting over the investigated area was not fully achieved but does not introduce further error since the laser extinction technique is based on an intensity ratio measurement (see Eq. (3)). Furthermore, other errors such as the precision of the fraction of the light deflected by the beam splitter will also be absorbed within ratios. This applies both to $\mathrm{CH}^{*}$ and light extinction measurements.

A detailed analysis of $\mathrm{CH}^{*}$ chemiluminescence and soot emission measurements showed that soot emission does not contribute significantly to the $\mathrm{CH}^{*}$ emission measurement $(\lambda=$ $431 \mathrm{~nm})$. A more detailed discussion will be presented later in the context of the experimental results.

Microgravity conditions were obtained on board of the Novespace A300-zeroG, which enables microgravity duration of $22 \mathrm{~s}$ with a quality of $10^{-2} \mathrm{~g}_{0}$. This microgravity period is long enough to reach steady state conditions. A detailed evaluation of the transient period is provided by Vietoris et al. (2000) who performed 180 second microgravity experiments on board of a sounding rocket and observed only minor differences with parabolic flight tests. The presence of g-jitter will have an effect on the results. This effect is difficult to quantify but was minimized by choosing images where gravity perturbations were the smallest and by averaging short sequences of 10 images. Rouvreau et al. (2004) provide a numerical evaluation of the impact on the flow field showing that high frequency gravity variations have very minor impact on the flame. Only low frequency high amplitude variations affect the flow field in an important manner. The low frequency, high amplitude variations can be identified from 
accelerometer readings and images were chosen not to correspond to these periods.

\section{Methodology}

\subsection{Laser extinction measurement}

According to Bouguer's law, the extent of the light intensity $i$ extinction along a path from 0 to $L_{y}$ and parallel to the $y$ axis (see FIG. 1), is given by the following ratio:

$$
\frac{i_{\lambda}\left(x, L_{y}, z\right)}{i_{\lambda}(x, 0, z)}=e^{-\int_{0}^{L_{y}} k_{\lambda}(x, y, z) d y}
$$

where $k_{\lambda}(x, y, z)$ is the local spectral extinction coefficient. Extinction is composed of absorption and scattering but if scattering can be neglected, Bouguer's law can be reduced to the following equation:

$$
\frac{i_{\lambda}\left(x, L_{y}, z\right)}{i_{\lambda}(x, 0, z)}=e^{-\int_{0}^{L_{y}} a_{\lambda}(x, y, z) d y}
$$

where $a_{\lambda}(x, y, z)$ is the local spectral absorption coefficient.

Laser extinction measurements can be performed to map the soot volume fraction $f_{\text {soot }}(x, z)$,

if the soot distribution is two-dimensional, i.e. if $\frac{\partial f_{\text {soot }}}{\partial y} \ll \frac{\partial f_{\text {soot }}}{\partial x}$ and $\frac{\partial f_{\text {soot }}}{\partial y} \ll \frac{\partial f_{\text {soot }}}{\partial z}$. In other words, if the soot volume fraction can be assumed uniform in the $y$ direction.

The two-dimensional assumption eliminates the dependency of the spectral absorption coefficient on $y$ and leads to directly infer the local spectral absorption coefficient $a_{\lambda}(x, z)$ 
from a measurement $A_{\lambda}(x, z)$, called here extinction factor:

$$
a_{\lambda}(x, z)=-\frac{1}{L_{y}} A_{\lambda}(x, z)=-\frac{1}{L_{y}} \log \left(\frac{i_{\lambda}\left(x, L_{y}, z\right)}{i_{\lambda}(x, 0, z)}\right)
$$

Chopping the laser source allows to subtract an image with no backlight (flame emission) from a backlit one (flame emission + laser light) and a correct extinction measurement can be made. Under such assumptions, Mie's theory shows that for "small" particles (Rayleigh limit), measurements at a single wavelength $\lambda$ should be sufficient to establish a relationship between the local spectral absorption coefficient curve and the soot volume fraction (Dalzell and Sarofim, 1969):

$$
\frac{a_{\lambda}(x, z)}{f_{\text {soot }}(x, z)}=\frac{36 n_{\lambda}^{2} \kappa_{\lambda} \pi}{\left(n_{\lambda}^{2}\left(1-\kappa_{\lambda}^{2}\right)+2\right)^{2}+4 n_{\lambda}^{4} \kappa_{\lambda}^{2}} \frac{1}{\lambda}
$$

where $n_{\lambda}$ and $\kappa_{\lambda}$ are respectively the real and the imaginary parts of the refractive index at the considered wavelength. Many studies have provided accurate measurements of the soot refractive index of which three are commonly cited: Dalzell and Sarofim (1969); Lee and Tien (1981); Habib and Vervisch (1988). For the present study, Habib and Vervisch's indexes were preferred mainly because these authors worked with ethylene (as in the present study and in contrast to Dalzell and Sarofim) and because the necessary mean particle diameter was determined by Diffusion Broadening Spectroscopy, thus making no assumption about refractive indexes for the calculations. If two-wavelength extinction diagnostics are used (Lee and Tien, 1981), iterations are necessary because the refractive indexes are also an input to 
the equations.

Two main assumptions have been made so far and will be discussed in the following sections: first, soot morphology corresponds to the requirements of Mie's theory for small particles and second, soot concentrations are only two-dimensional. The latter is clearly incorrect so the magnitude of the error introduced by burner edge effects will be assessed and a correction methodology proposed.

\subsection{Soot morphology}

Figures 2(a) and 2(b) present pictures obtained by means of a Scanning Electron Microscope. A stainless steel wire mesh was inserted in the flame for half a second, as prescribed by Dobbins and Megaridis (1987), and in this way soot samples were obtained. Figure 2(a) represents sampling at $x=55 \mathrm{~mm}$ (see FIG. 1 for location). This photograph shows some primary particles observed at that specific location. Two important conclusions can be drawn. First, particles are spheres, which makes the first Mie's assumption valid. Second, the common criterion that enables the use of Mie's theory for "small" particles and makes diffusion negligible. The criterion states that:

$$
\frac{\pi D}{\lambda} \leq 0.3
$$

where $D$ is the particle diameter. For the present particles, a statistical counting was performed on several pictures taken at $x=55 \mathrm{~mm}$ to generate the graph shown in Figure 3. For simplicity, the size distribution of soot particles is divided only in two regions, defining on 
the left the region where particles diameter complies with the above criterion. Knowing that $\lambda=532 \mathrm{~nm}$, more than $85 \%$ of the particles can be considered as "small" from a radiative point of view. Thus, the set of assumptions necessary to map the soot volume fraction is found to be valid. Particles sampled upstream were observed to be smaller thus Mie's theory is expected to be valid throughout the length of the burner.

However, these assumptions break down as soot agglomerates downstream of the burner (FIG. 2(b)). Downstream of the burner, primary soot particles agglomerate and they loose their spherical nature. These observations are consistent with previous microgravity studies (Köylü and Faeth, 1994).

\section{$3.3 \mathrm{CH}^{*}$ chemiluminescence}

$\mathrm{CH}^{*}$ radicals have been proved (Najm et al., 1998; Devriendt et al., 1996) to be central to many hydrocarbon combustion chemical pathways as they originate from the reaction between $\mathrm{O}_{2}$ and $\mathrm{C}_{2} \mathrm{H}$. These excited radicals go back to ground-state either through collisional quenching or through spontaneous fluorescence, whose $\mathrm{A}^{2} \Delta \rightarrow \mathrm{X}^{2} \Pi$ transition occurs at $\lambda=431.4 \mathrm{~nm}$. Therefore, $\mathrm{CH}^{*}$ chemiluminescence measurements can be directly related to the burning rate (Higgins et al., 2001; Berg et al., 2000; Blevins et al., 1999). Quantitative results can be achieved for pre-mixed flames where the local equivalence ratio can be tuned so that reactant concentrations entering the reaction zone are accurately known. While being cautious about extrapolating to diffusion flames, some results are of interest. For instance, Berg et al. (2000) and Higgins et al. (2001) noticed that $\mathrm{CH}^{*}$ chemiluminescence increased when approaching the stoechiometric equivalence ratio and that this tendency was even 
more noticeable for pressures close to atmospheric. This provides evidence that for these experimental conditions the signal to noise ratio will be high.

Based on Hurle's earlier work (Hurle et al., 1968), McManus et al. (1995) assumed that the volumetric rate of heat release $\dot{\omega}$ is proportional to the $\mathrm{CH}^{*}$ chemiluminescence intensity $I:$

$$
\dot{\omega}=\beta I
$$

For a quantitative measurement, $\beta$ can be determined by performing the enthalpy balance of the burner. However, this kind of balance is difficult to perform during parabolic flights since the determination of the enthalpy balance requires a detailed chemical analysis. Nevertheless, $\beta$ should be a constant value for fixed experimental conditions. Thus, it is possible to plot relative variations of the local chemiluminescence intensities.

The structure of the overall reaction zone can be captured by two two-dimensional $\mathrm{CH}^{*}$ chemiluminescence images. The incoming energy recorded by each pixel of the CCD camera is proportional to the solid angle of view $\Omega$ over which light is collected, to the overall efficiency of the optics, $\eta$, and to the intensity integrated over the line-of-sight. A side view of the flame will provide the emission integrated over the width of the flame $\left(w i d t h_{y}\right)$ for each pixel located at a specific $(x, z)$ position. Thus, at each location $x$, the $z$-distribution $S_{x}(z)$ of the recorded emission is given by:

$$
S_{x}(z)=\frac{\Omega_{\text {side }}}{4 \pi} \eta_{\text {side }} \int_{\text {width }_{y}} I(x, y, z) d y
$$

In a similar manner, looking at the burner from above, the $y$-distribution $S_{x}(y)$ of the 
emission measured is given by the following equation:

$$
S_{x}(y)=\frac{\Omega_{t o p}}{4 \pi} \eta_{\text {top }} \int_{\text {height }_{z}} I(x, y, z) d z
$$

where $h_{e i g h t}$ is the integration path length along the $z$-axis.

Integrating over the complementary variable and dividing both expressions we obtain:

$$
\frac{\int_{\text {height }_{z}} S_{x}(z) d z}{\int_{\text {widthy }_{y}} S_{x}(y) d y}=\frac{\Omega_{\text {side }}}{\Omega_{\text {top }}} \frac{\eta_{\text {side }}}{\eta_{\text {top }}} \frac{\int_{\text {height }_{z}} \int_{\text {width }_{y}} I(x, y, z) d y d z}{\int_{\text {width }_{y}} \int_{\text {height }_{z}} I(x, y, z) d z d y}=\alpha
$$

In the second term of equation (9), the integrals in the numerator and denominator correspond both to the total $\mathrm{CH}^{*}$ energy emission, thus $\alpha$ is given only by the ratio of the solid angles and efficiencies. If identical cameras and relative flame-camera locations were used, then $\alpha$ should be equal to unity. The use of a beam splitter as well as constraints imposed by the experimental conditions will result in a constant experimental value of $\alpha$ significantly different from unity.

Assuming that the integration path length height $z$ in the $z$ direction is the flame stand-off distance, as recorded from the side view of the flame, the top left integral (equation (9)) can be calculated. The path length width in the $y$ direction, and thus the bottom left integral (equation (9)), is more difficult to establish, thus requires a more involved treatment that will be discussed later. A visible top view will not provide this information because the locations of maximum extinction and peak of $\mathrm{CH}^{*}$ and visible emissions do not match. This will also be alluded in the paragraph below. 
Differentiation between soot and $\mathrm{CH}^{*}$ emission is essential for the present measurements to be valid. Given the wide band nature of the soot emission, it is possible that $\mathrm{CH}^{*}$ measurements be affected by soot emission and that extinction measurements be affected by $\mathrm{CH}^{*}$ emission. The latter can be discarded because total emissions are subtracted from the absorption measurements. Furthermore, there is little spatial overlap between the $\mathrm{CH}^{*}$ emissions zone and region where soot can be found. To illustrate this, an example of $\mathrm{CH}^{*}$ and raw absorption measurements is presented in Figure 4. Figure 4 shows a comparison at a given streamwise coordinate between $\mathrm{CH}^{*}$ emission and local "absorption" coefficient. Emission has not been subtracted here from the backlit images, so the region with negative coefficients reveals a strong emission zone. The positive coefficient peak $(z=7 \mathrm{~mm})$, i.e. the maximum of soot concentration, stands quite far from the $\mathrm{CH}^{*}$ peak $(z=16 \mathrm{~mm})$. The contribution of soot emission to $\mathrm{CH}^{*}$ measurements can be assessed by comparing $\mathrm{CH}^{*}$ measurements in the flame region and after the flame has quenched. Figure 5 shows measured $\mathrm{CH}^{*}$ and visible emission profiles for two different streamwise coordinates. For $x=8 \mathrm{~mm}$ (Fig. 5(a)), the upper part of the light emission profile $(z \geq 5 \mathrm{~mm})$ is mainly due to the $\mathrm{CH}^{*}$ emission while the remaining part $(z \leq 5 \mathrm{~mm})$ corresponds to soot emission. For $x=80 \mathrm{~mm}$ (Fig. $5(\mathrm{~b}))$, the $\mathrm{CH}^{*}$ reaction zone has vanished while the light emission profile is kept almost at the same intensity peak. Thus, the small signal peak measured through the $431 \mathrm{~nm}$ filter at $x=80 \mathrm{~mm}$ can be attributed to the soot contribution to the $\mathrm{CH}^{*}$ measurements and thus the magnitude of the required correction could be inferred. This would imply a correction of less than $1 \%$, therefore, no correction for soot emission was applied to $\mathrm{CH}^{*}$ measurements. 


\section{Results and discussion}

\subsection{Reaction zone structure}

A single set of $\mathrm{CH}^{*}$ chemiluminescence measurements is presented in Figures 6 to illustrate the results.

Experimental curves showed that the data are distributed in a symmetrical way with respect to the $y=0$ plane, so only one side of the curves is presented. The term "width" is to be understood as width at half the height of the curve.

Figure 6(a) shows that the reaction zone and the peak intensity are small close to the leading edge of the burner, increasing in intensity and width with the distance downstream until they reach a maximum at approximately $x=25 \mathrm{~mm}$. For $25 \mathrm{~mm} \leq x \leq 45 \mathrm{~mm}$, the peak intensity decays but the region showing $\mathrm{CH}^{*}$ emissions continues to increase. As the end of the porous burner is reached $(x \geq 45 \mathrm{~mm})$, the magnitude decays and the width of the reactive zone shows a further increase. Side measurements presented for different heights ( $z$ coordinate) in Figure 6(b) show the same tendencies for the side view.

A simple analytical way to quantify the integrals presented in equation (9) is by approximating the curves in Figures 6. The curves in Figure 6(b) can be approximated by a gaussian function whose characteristic length scale is $\Delta z$, the width at $\frac{\operatorname{Max} z}{2}$. The curves of Figure 6(a) can be approximated by a top hat function over $-25 \mathrm{~mm} \leq y \leq 25 \mathrm{~mm}$, corresponding to the peak intensity, $\operatorname{Max}_{y}$. For $y \leq-25 \mathrm{~mm}$ and $y \geq 25 \mathrm{~mm}$, half a gaussian function is added at each side. The characteristic length scale of the gaussian function is $\Delta y$, which is 
the width at $\frac{M a x_{y}}{2}$. The left hand side of equation (9) can then be re-written as follows:

$$
\frac{\left(\frac{\pi}{\log 2}\right)^{1 / 2} \frac{\Delta z \operatorname{Max}_{z}}{2}}{\left(\frac{\pi}{\log 2}\right)^{1 / 2} \frac{\Delta y \operatorname{Max}_{y}}{2}+50 \operatorname{Max}_{y}}=\alpha
$$

The measurements presented in Figures 6 are introduced into equation (9) and the calculated value of $\alpha$ is presented in Figure 7. A constant value of $\alpha=0.12$ is revealed from the measurements for $20 \mathrm{~mm} \leq x \leq 55 \mathrm{~mm}$. A departure from the constant value is observed close to the leading edge due to the proximity of the burner surface which biases the top view measurements $(x \leq 15 \mathrm{~mm})$. A decay is observed downstream of the trailing edge of the burner. This decay is justified by the complex nature of the flow in this region (Rouvreau et al., 2002) which strongly departs from the assumptions of this work. The constant nature of $\alpha$ validates the assumptions leading to equation (9).

For purposes of this work, it is convenient to separate in the $\mathrm{CH}^{*}$ top view measurements the contributions of the top hat region and those of the decaying sides assumed to be gaussian. The decaying sides represent the three-dimensional contributions to the measured side intensities of $\mathrm{CH}^{*}$ chemiluminescence. The peak value, $\mathrm{Max}_{z}$, will not include a three-dimensional contribution given it occurs close to the flame stand-off distance, nor will the region above the location of $\operatorname{Max}_{z}$ (called "three-dimensional free region" in Figure $6(\mathrm{~b})$ and given for the curve at $x=45 \mathrm{~mm}$ ). In contrast, the region below the location of $\operatorname{Max}_{z}$ (called "three-dimensional affected region" in Figure 6(b)) will be affected by the three-dimensional region of the flame. Given the nature of equation (10), it is simpler to represent the correction by decreasing the width of the inner part of the curves presented 
in Figure 6(b) instead of correcting the magnitude of the emission at each specific location. This comes from the structure of equation (10) that can be reformulated to extract the value of $\Delta z$, which leads to:

$$
\Delta z=\alpha \frac{\operatorname{Max}_{y}}{\operatorname{Max}_{z}} \Delta y+\frac{100 \alpha}{\operatorname{Max}_{z}}\left(\frac{\log 2}{\pi}\right)^{1 / 2} \operatorname{Max}_{y}
$$

Thus, the measured $\mathrm{CH}^{*}$ intensity width $\Delta z$ appears as the sum of two contributions:

- $\frac{100 \alpha}{M a x_{z}}\left(\frac{\log 2}{\pi}\right)^{1 / 2} \operatorname{Max}_{y}$, the contribution of the two-dimensional top hat function;

- $\alpha \frac{\operatorname{Max}_{y}}{\operatorname{Max}_{z}} \Delta y$, the three-dimensional contribution from the decaying sides of width $\Delta y$.

If three-dimensional effects were to be eliminated from the $\mathrm{CH}^{*}$ measurements then this could be done by correcting the inner part of any of the curves by the corrective term $\Delta z_{C}=\alpha \frac{\operatorname{Max}_{y}}{\operatorname{Max}_{z}} \Delta y$. Thus the corrected width of the curve at $\frac{\operatorname{Max} z}{2}$ would be:

$$
\Delta z_{\text {corr }}=\Delta z-\alpha \frac{\operatorname{Max}_{y}}{\operatorname{Max}_{z}} \Delta y=\Delta z-\Delta z_{C}
$$

By analogy, this correction will be applied to soot extinction cross-sections. Physically, this extrapolation is justified by the strong influence of $\mathrm{CH}^{*}$ radicals within the first steps of fuel cracking which are the very beginning of soot formation history. Thus an increase in $\mathrm{CH}^{*}$ production can be directly linked to an increase in soot concentration. Furthermore, away from extinction, chemistry can be assumed fast, and $\mathrm{CH}^{*}$ and soot formation will be governed by the same transport equations. Thus $\mathrm{CH}^{*}$ emission and soot absorption distributions should be defined by the same geometric factors. 


\subsection{Soot layer structure}

Figure 8 displays in the top right corner an instantaneous greyscale frame of the CCD recordings used for the extinction measurements presented on the main plot. It can be observed that the soot layer (dark zone) can be found under the zone of flame emission and grows in thickness with $x$. Close to the flame leading edge $(x \leq 20 \mathrm{~mm})$ the extinction factor increases rapidly, it stabilizes for $20 \mathrm{~mm} \leq x \leq 55 \mathrm{~mm}$ and then starts to increase again beyond the trailing edge of the burner $(x \geq 60 \mathrm{~mm})$.

For a given curve, e.g. for a given $x$ location, $z_{\max }$ defines the location of the extinction coefficient maximum. For $z \geq z_{\max }$, the curve can be seen to keep analogous shapes. As explained for $\mathrm{CH}^{*}$ emission measurements, here, the rays can be assumed to pass through the flame unaffected by three-dimensional effects. For $z \leq z_{\max }$, where flame curves towards the burner surface, soot extinction coefficients were corrected using a correction factor based on the analysis presented in the previous section. A second order polynomial is used to define the correction, $\Delta a_{\lambda}(z)$ :

$$
\Delta a_{\lambda}(z)=c_{2} z^{2}+c_{1} z+c_{0}
$$

and the following conditions were used to derive the necessary three constants.

For $z=z_{\text {max }}, \Delta a_{\lambda}=0$, as no correction is required at this point.

For $z=0, \Delta a_{\lambda}$ is defined such as $a_{\lambda}=0$, assuming no soot immediately above the porous burner. Finally, at mid height of the curve, the position $z$ is shifted by the corrective term 
given in equation (12) and normalized as indicated in the following equations:

$$
\left(\frac{\Delta z_{\text {corr }}-\Delta z}{\Delta z}\right)_{C H^{*}}=\left(\frac{\Delta z_{\text {corr }}-\Delta z}{\Delta z}\right)_{\text {soot absorption }}
$$

or equivalently

$$
\left(\frac{\Delta z_{C}}{\Delta z}\right)_{C H^{*}}=\left(\frac{\Delta z_{C}}{\Delta z}\right)_{\text {soot absorption }}
$$

Eventually, for all conditions studied, the correction never exceeded $12 \%$.

\subsection{Discussion}

The experimental results show distinctive trends for the soot volume fractions and $\mathrm{CH}^{*}$ emissions. The $\mathrm{CH}^{*}$ data presented in Figure 6(b) shows that the reaction intensity first increases, reaches a peak and then decreases as the distance from the leading edge of the burner increases beyond $x \geq 25 \mathrm{~mm}$. In contrast, Figure 8 shows that soot continues to increase even beyond the burner trailing edge. Thus, soot formation is initially favoured but oxidation acquires a more significant role as $x$ increases. Eventually, soot concentrations will reach a critical value, the flame will extinguish and soot oxidation will thus be hampered. A more rapid increase in soot concentration follows. These observations are consistent with measurements in axisymmetric flames that showed that soot concentrations continue to grow beyond the combustion reaction zone (Konsur et al., 1999b).

A systematic study of both light emission (at $\lambda=532 \mathrm{~nm}$ recorded from the unbacklit images used for absorption measurements) and corrected soot volume fractions was conducted for different fuel and oxidizer velocities. A series of representative values are presented in 
Figure 9 for two specific locations along the $x$-axis (Figure 9 (a) at $x=25 \mathrm{~mm}$ and Figure 9 (b) at $x=50 \mathrm{~mm}$ ). It can be seen that independent of the location, emissions increase with the oxidizer flow. The range of velocities presented is consistent with that where Vietoris et al. (2000) and Brahmi et al. (1998) observed an increase in the intensity of the visible flame. They named this region as the transitional region between blue and yellow flames. Because of the enhancement of convection the oxidizer streamlines penetrate deeper into the fuel region resulting in enhanced soot oxidation and thus increased luminous intensity. The observed colour shifts from the "blue" towards the "yellow". Rouvreau et al. (2002) numerically demonstrated this process by presenting the evolution of the streamlines with the oxidizer flow rate.

Contradictory to the above explanations seem to be the soot concentration trends. Despite the enhanced oxidation soot volume fractions grow with the oxidizer velocity. Detailed observation of Figure 9 shows that together with this increase in soot volume fraction, the light emission and soot volume fraction peaks separate as the velocity increases. It seems, therefore, that an increase in oxidizer flow results both in an increase in oxidation and soot formation, with the later dominating in this regime.

In contrast to the effect of the oxidizer velocity, an increase in the fuel injection velocity results only in an increase in the soot volume fraction, with $\mathrm{CH}^{*}$ intensity remaining almost constant. The transition from "blue" to "yellow" flames is also not observed experimentally in this case (Vietoris et al., 2000; Brahmi et al., 1998). Fuel injection increases soot production but has a negligible effect on oxidation. Rouvreau et al. (2002) confirmed the minor effect of fuel injection on the streamlines close to the flame. 
Low frequency, high amplitude perturbations in the gravity level were found to be the very main source of experimental uncertainties. Treatment of more than 10 image groups allowed to define error bars for the soot volume fraction measurements. These are presented in Figure 9 (b) and represent the maximum deviations from the average. As expected, the faster the oxidizer velocity is, the more the influence of gravity perturbations is reduced. Eventually, the highest uncertainties on the soot volume fraction measurement appears to be in the order of $12 \%$ and corresponds to $V_{o x}=100 \mathrm{~mm} \cdot \mathrm{s}^{-1}$. Similar treatment was done with $\mathrm{CH}^{*}$ measurements indicating significantly smaller error bars, therefore these are not presented here.

\section{Conclusion}

This study has provided a methodology to correct cross-sections of soot volume fractions for microgravity laminar diffusion flames obtained with a non-axisymmetric burner. This was necessary because soot production and oxidation are intimately linked to the structure of the streamlines close to the flame.

A correction was made through $\mathrm{CH}^{*}$ radicals emission measurements. These measurements were obtained from two orthogonal views to quantify three-dimensional effects. The correction was extrapolated to the soot field. For all conditions studied the correction never exceeded $12 \%$.

Within the region located right above the burner, the soot volume fraction and soot emission were compared. The results showed that soot oxidation and soot formation increase with the oxidizer velocity. Thus, increasing oxidizer velocity may not result in an increase of 
combustion completeness. Fuel injection results only in an increase of soot formation. These results are in agreement and complement previous experimental observations and numerical results (Vietoris et al., 2000; Brahmi et al., 1998; Rouvreau et al., 2002).

\section{Acknowledgements}

This work was funded by CNES and ESA. Parabolic flights campaigns took place on board the Novespace A300-zeroG.

\section{REFERENCES}

Berg, P.A., Hill, D.A., Noble, A.R., Smith, G.P., Jeffries, J.B., and Crosley, D.R. (2000), Absolute $\mathrm{CH}$ concentration measurements in low-pressure methane flames: Comparisons with model results, Combust. Flame, 121, 223.

Blevins, L.G., Renfro, M.W., Lyle, K.H., Laurendeau, N.M., and Gore, J.P. (1999), Experimental study of temperature and $\mathrm{CH}$ radical location in partially premixed $\mathrm{CH}_{4} /$ air coflow flames, Combust. Flame, 118, 684.

Brahmi, L., Vietoris, T., Joulain, P., and Torero, J.L. (1998), Détermination par caméra infrarouge des distributions de température sur l'enveloppe d'une flamme de diffusion établie sur un brûleur plat en microgravité.

Dalzell, W.H. and Sarofim, A.F. (1969), Optical constants of soot and their applications to heat flux calculations, J. Heat Transfer, 91, 100.

Devriendt, K., Van Look, H., Ceurters, B., and Peeters, J. (1996), Kinetics of formation of 
chemiluminescent $\mathrm{CH}\left(\mathrm{A}^{2} \Delta\right)$ by the elementary reactions of $\mathrm{C}_{2} \mathrm{H}\left(\mathrm{X}^{2} \Sigma^{+}\right)$with $\mathrm{O}\left({ }^{3} \mathrm{P}\right)$ and $\mathrm{O}_{2}\left(\mathrm{X}^{3} \Sigma_{\mathrm{g}}^{-}\right)$: a pulse laser photolysis study, Chem. and Phys. Letter, 261, 450.

Dobbins, R.A. and Megaridis, C.M. (1987), Morphology of flame-generated soot as determined by thermophoretic sampling, Langmuir, 3, 254.

Fernandez-Pello, A.C., Walther, D.C., Cordova, J.L., Steinhaus, T., Quintiere, J.G., Torero, J.L., and Ross, H. (2000), Test method for ranking materials flammability in reduced gravity, Space Forum, 6, 237.

Habib, Z.G. and Vervisch, P. (1988), On the refractive index of soot at flame temperature, Combust. Sci. Technol., 59, 261.

Higgins, B., McQuay, M.Q., Lacas, F., and Candel, S. (2001), An experimental study on the effect of pressure and strain rate on $\mathrm{CH}$ chemiluminescence of premixed fuel-lean methane/air flames, Fuel, 80, 1583.

Hurle, I.R., Price, R.B., Sugden, T.M., and Thomas, A. (1968), Sound emission form open turbulent premixed flames, Proc. Roy. Soc. (Lond.), A303, 409.

Konsur, B., Megaridis, C.M., and Griffin, D.W. (1999a), Fuel preheat effects on soot-field structure in laminar gas jet diffusion flames burning in 0-g and 1-g, Combust. Flame, 116, 334.

Konsur, B., Megaridis, C.M., and Griffin, D.W. (1999b), Soot aerosol properties in laminar soot-emitting microgravity nonpremixed flames, Combust. Flame, 118, 509.

Köylü, Ü. Ö. and Faeth, G.M. (1994), Optical properties of overfire soot in buoyant turbulent diffusion flames at long residence times, J. Heat Transfer, 116, 152. 
Lee, S.C. and Tien, C.L. (1981), Optical constants of soot in hydrocarbon flames, Proc. Combust. Inst., 18, 1159.

Legros, G. (2003), Etude du comportement radiatif d'une flamme de diffusion établie en micropesanteur, PhD report, Université de Poitiers, France.

Lin, K.C. and Faeth, G.M. (1999), Shapes of nonbuoyant round luminous laminar jet diffusion flames in coflowing air, AIAA Journal, 37, 759.

Lin, K.C., Faeth, G.M., Sunderland, P.B., Urban, D.L., and Yuan, Z.G. (1999), Shapes of nonbuoyant round luminous hydocarbon/air laminar jet diffusion flames, Combust. Flame, 116, 415 .

Markstein, G.H. and De Ris, J. (1984), Radiant emission and absorption by laminar ethylene and propylene diffusion flames, Proc. Combust. Inst., 20, 1637.

McManus, K., Yip, B., and Candel, S. (1995), Emission and laser-induced fluorescence imaging in experimental combustion, Exp. Thermal and Fluid Science, 10, 486.

Megaridis, C.M., Konsur, B., and Griffin, D.W. (1996), Soot-field structure in laminar sootemitting microgravity nonpremixed flames, Proc. Combust. Inst., 26, 1291.

Mortazavi, S., Sunderland, P.B., Jurng, J., Köylü, Ü.Ö., and Faeth, G.M. (1993), Structure of soot-containing laminar jet diffusion flames, AIAA paper, 93-0708.

Najm, H.N., Mueller, C.J., and Wyckoff, P.S. (1998), On the adequacy of certain experimental observables as measurements of flame burning rate, Combust. Flame, 113, 312.

Olson, S.L. and T'ien, J.S. (2000), Buoyant low-stretch diffusion flames beneath cylindrical pmma samples, Combust. Flame, 121, 439. 
Rouvreau, S., Cordeiro, P., Torero, J.L., and Joulain, P. (2004), Influence of the g-jitter on a laminar boundary layer type diffusion flame, Proc. Combust. Inst., 30, to appear.

Rouvreau, S., Joulain, P., Wang, H.Y., Cordeiro, P., and Torero, J.L. (2002), Numerical evaluation of boundary layer assumptions used for the prediction of the stand-off distance of a laminar diffusion flame, Proc. Combust. Inst., 29, 2527.

Sunderland, P.B., Mortazavi, S., Faeth, G.M., and Urban, D.L. (1994), Laminar smoke-point of nonbuoyant jet diffusion flames, Combust. Flame, 96, 97.

Torero, J.L., Vietoris, T., Legros, G., and Joulain, P. (2002), Estimation of a total mass transfer number from the stand-off distance of a spreading flame, Combust. Sci. Technol., $174,187$.

Urban, D.L., Griffin, D.W., and Gard, M.Y. (2000), Smoke-point properties of non-buoyant round laminar jet diffusion flames, Proc. Combust. Inst., 28, 1965.

Vietoris, T., Ellzey, J.L., Joulain, P., Mehta, S.N., and Torero, J.L. (2000), Laminar diffusion flame in micro-gravity: the results of the mini-texus 6 sounding rocket experiment, Proc. Combust. Inst., 28, 2883.

Xu, F., Dai, Z., and Faeth, G.M. (2002), Flame and soot boundaries of laminar jet diffusion flames, AIAA Journal, 40, 2439. 


\section{List of figure captions}

FIG. 1 Schematic of the experimental apparatus as seen from the direction of the oxidizer flow. A close-up of the burner is presented on the right.

FIG. 2 Scanning Electron Microscope pictures of soot particles sampled $\left(t_{\text {sampling }}=0.5 \mathrm{~s}\right)$ on a stainless steel wire mesh, at different streamwise coordinates: (a) at the end of the porous square $(x=55 \mathrm{~mm}$, $y=0 \mathrm{~mm}, z=12 \mathrm{~mm}$ ) and (b) at the end of the burner plate $(x=180 \mathrm{~mm}, y=0 \mathrm{~mm}, z=12 \mathrm{~mm})$.

Fig. 3 Size distribution of soot particles sampled at $x=55 \mathrm{~mm}$ and in the symmetry plane $(y=0)$.

FIG. 4 Comparison of local spectral absorption coefficient (solid line) and $\mathrm{CH}^{*}$ intensity (dashed line) at $x=25 \mathrm{~mm}$, for $V_{o x}=150 \mathrm{~mm} \cdot \mathrm{s}^{-1}$ and $V_{F}=6.4 \mathrm{~mm} \cdot \mathrm{s}^{-1}$. 
FIG. 5 Comparison of visible intensity (dashed line) and $\mathrm{CH}^{*}$ intensity (solid line) for $V_{o x}=150 \mathrm{~mm} \cdot \mathrm{s}^{-1}$ and $V_{F}=6.4 \mathrm{~mm} \cdot \mathrm{s}^{-1}$, (a) at $x=8 \mathrm{~mm}$ and (b) $x=80 \mathrm{~mm}$.

FIG. $6 \mathrm{CH}^{*}$ chemiluminescence intensity measurements for specific $x$ coordinate values and for $V_{F}=6.4 \mathrm{~mm} \cdot \mathrm{s}^{-1}$ and oxidizer $V_{o x}=$ $150 \mathrm{~mm} \cdot \mathrm{s}^{-1}$ : (a) Top view, (b) Side view.

FIG. 7 Ratio of the integrated $\mathrm{CH}^{*}$ chemiluminescence intensities (see equation (9)) versus $x$ streamwise coordinate, for $V_{F}=6.4 \mathrm{~mm} . \mathrm{s}^{-1}$ and $V_{o x}=150 \mathrm{~mm} \cdot \mathrm{s}^{-1}$.

Fig. 8 Cross-sections at different $x$ streamwise coordinate values. The plot corresponds to the extinction factor obtained from greyscale pictures of the laser extinction through the flame (example in the top right corner, where the igniting spark is visible). Data correspond to $V_{F}=6.4 \mathrm{~mm} \cdot \mathrm{s}^{-1}$ and $V_{o x}=150 \mathrm{~mm} \cdot \mathrm{s}^{-1}$.

FIG. 9 Soot volume fraction (solid lines) and emission (dashed lines) obtained at (a) $x=25 \mathrm{~mm}$ and at (b) $x=50 \mathrm{~mm}$ for different oxidizer velocities and $V_{F}=6.4 \mathrm{~mm} . \mathrm{s}^{-1}$. 


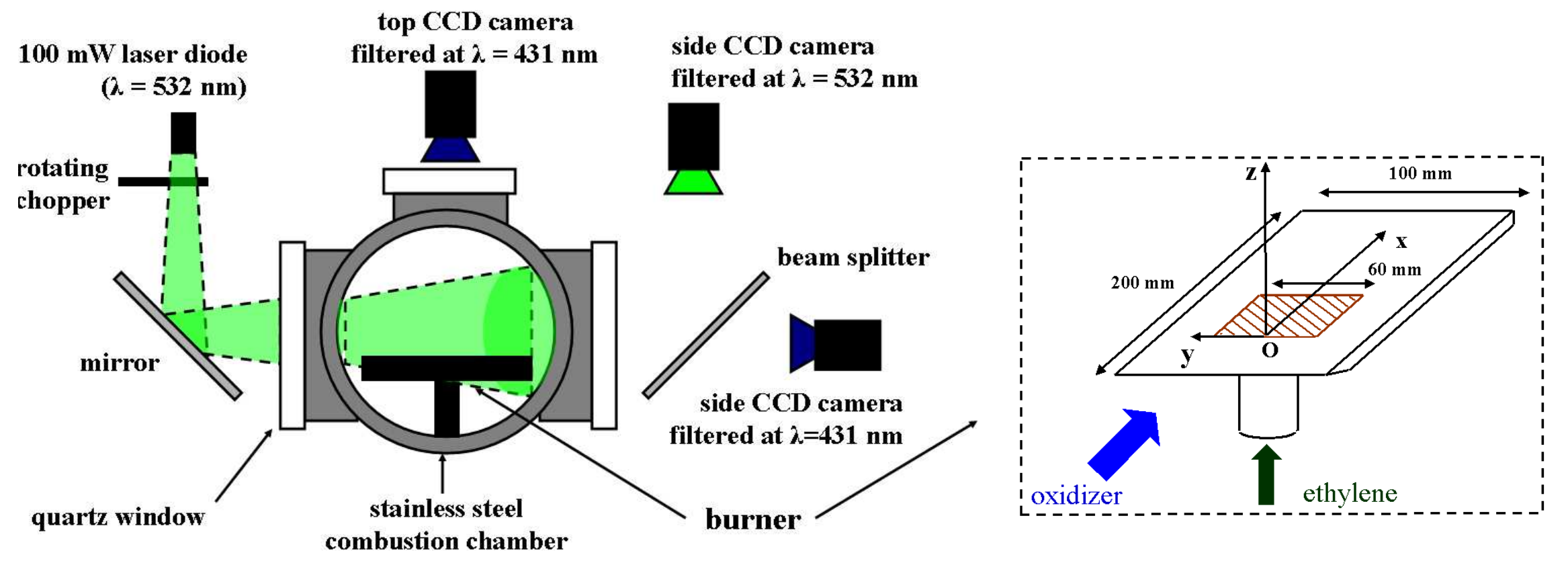

FIG. 1 - 


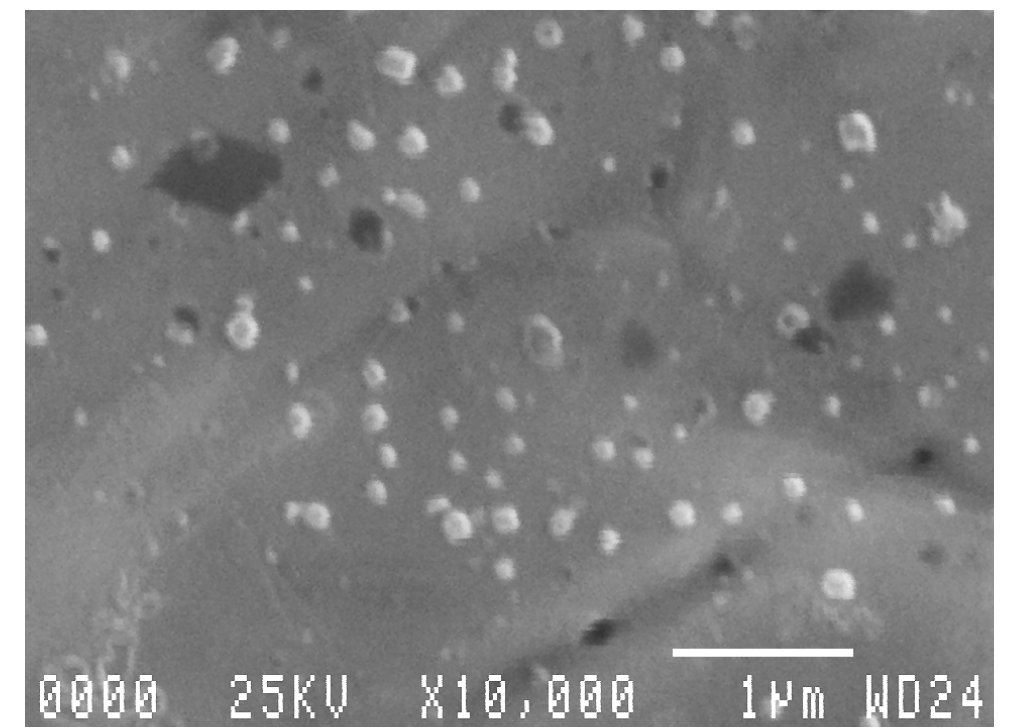

(a)

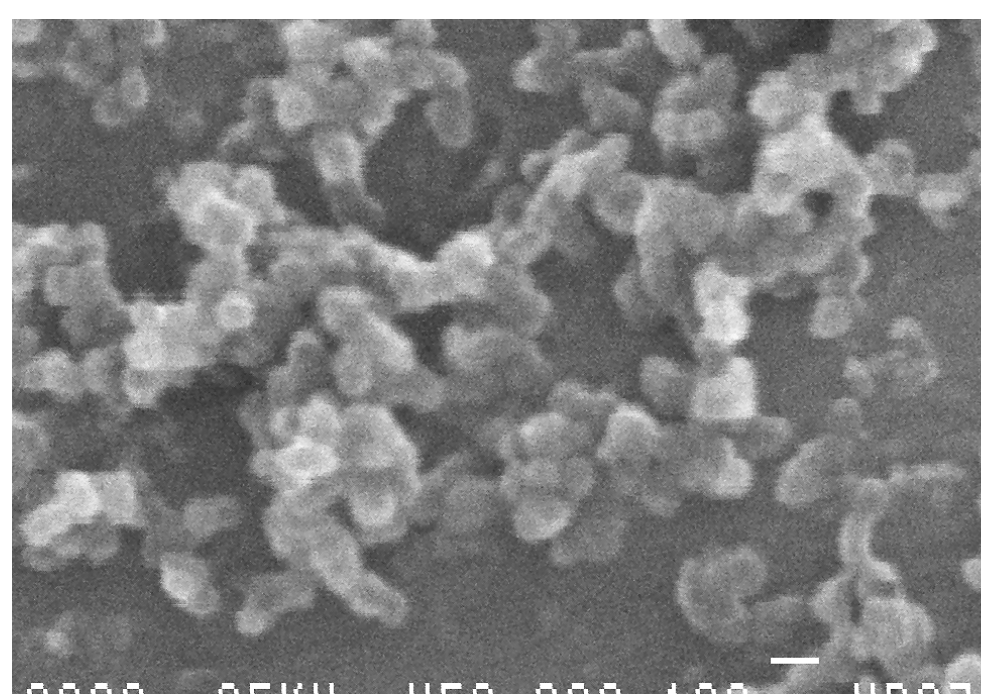

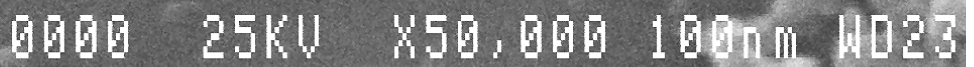
(b)

FIG. 2 
validity range for "small particles" theory

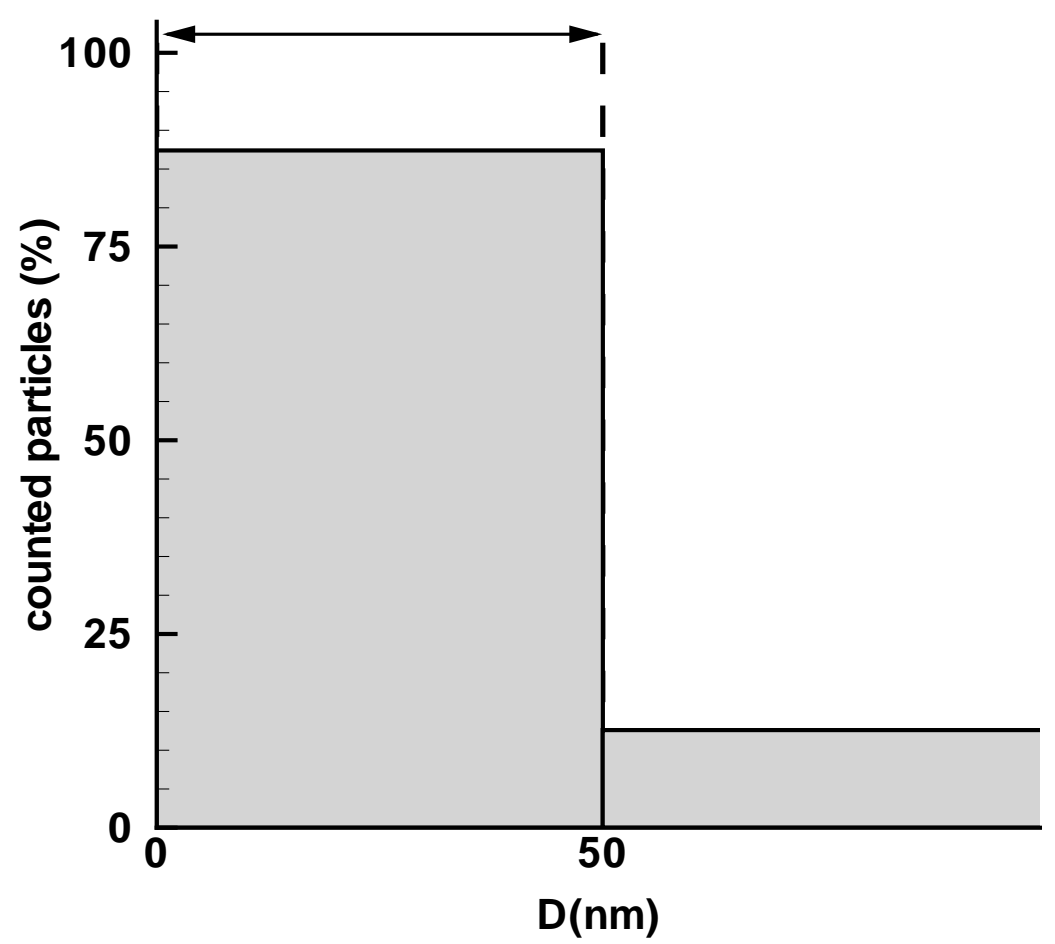

FIG. 3 - 


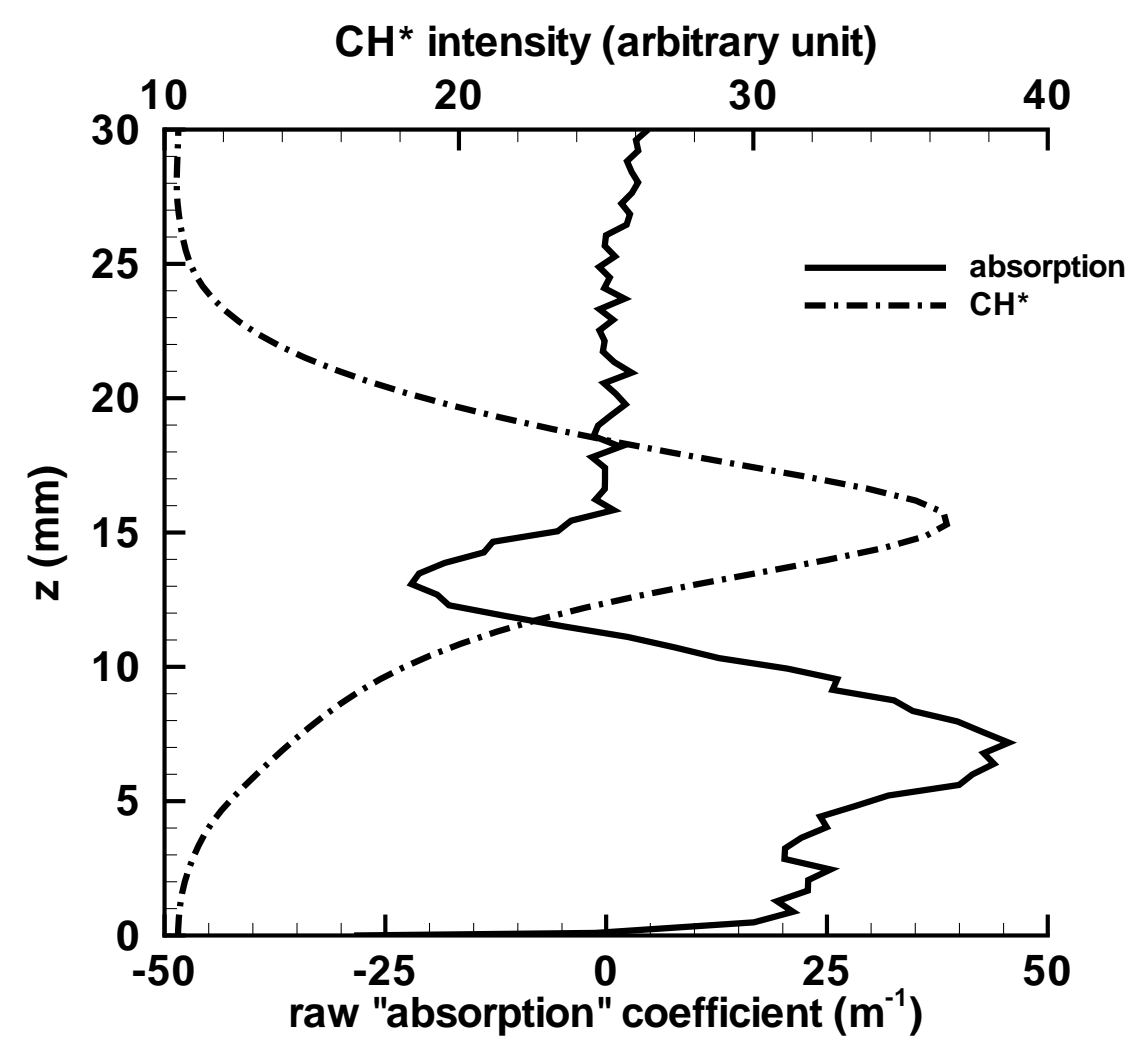

FIG. 4 - 


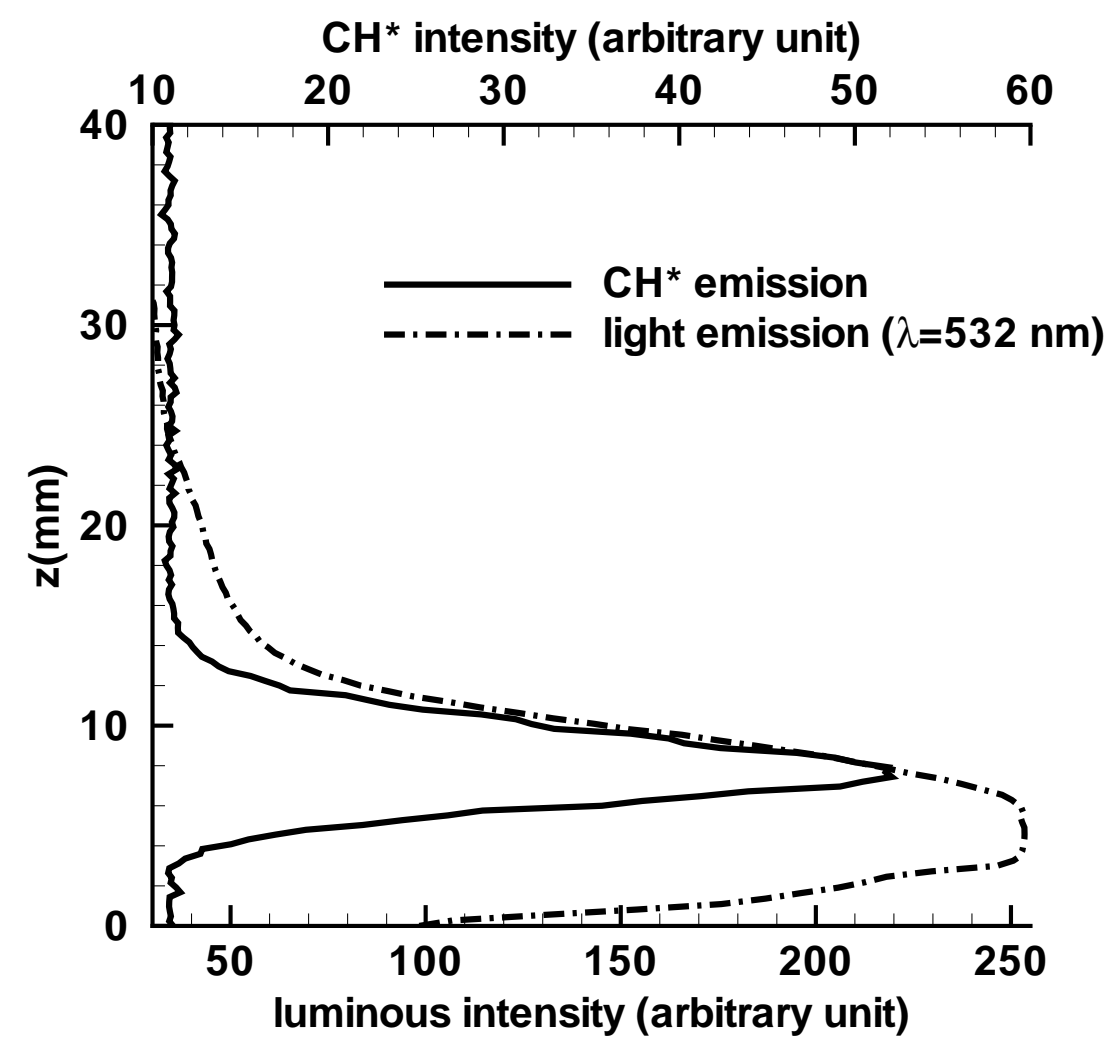

(a)

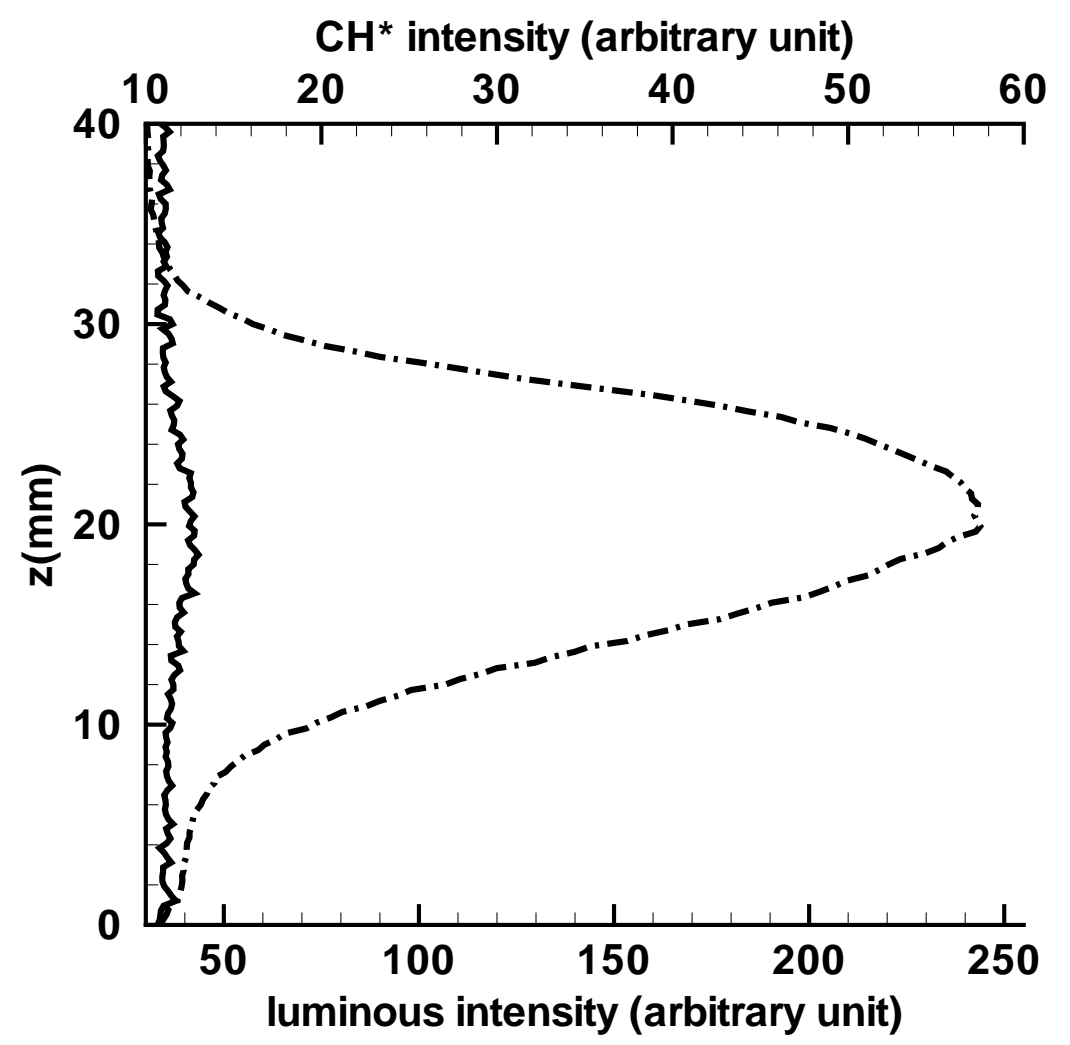

(b)

FIG. 5 - 


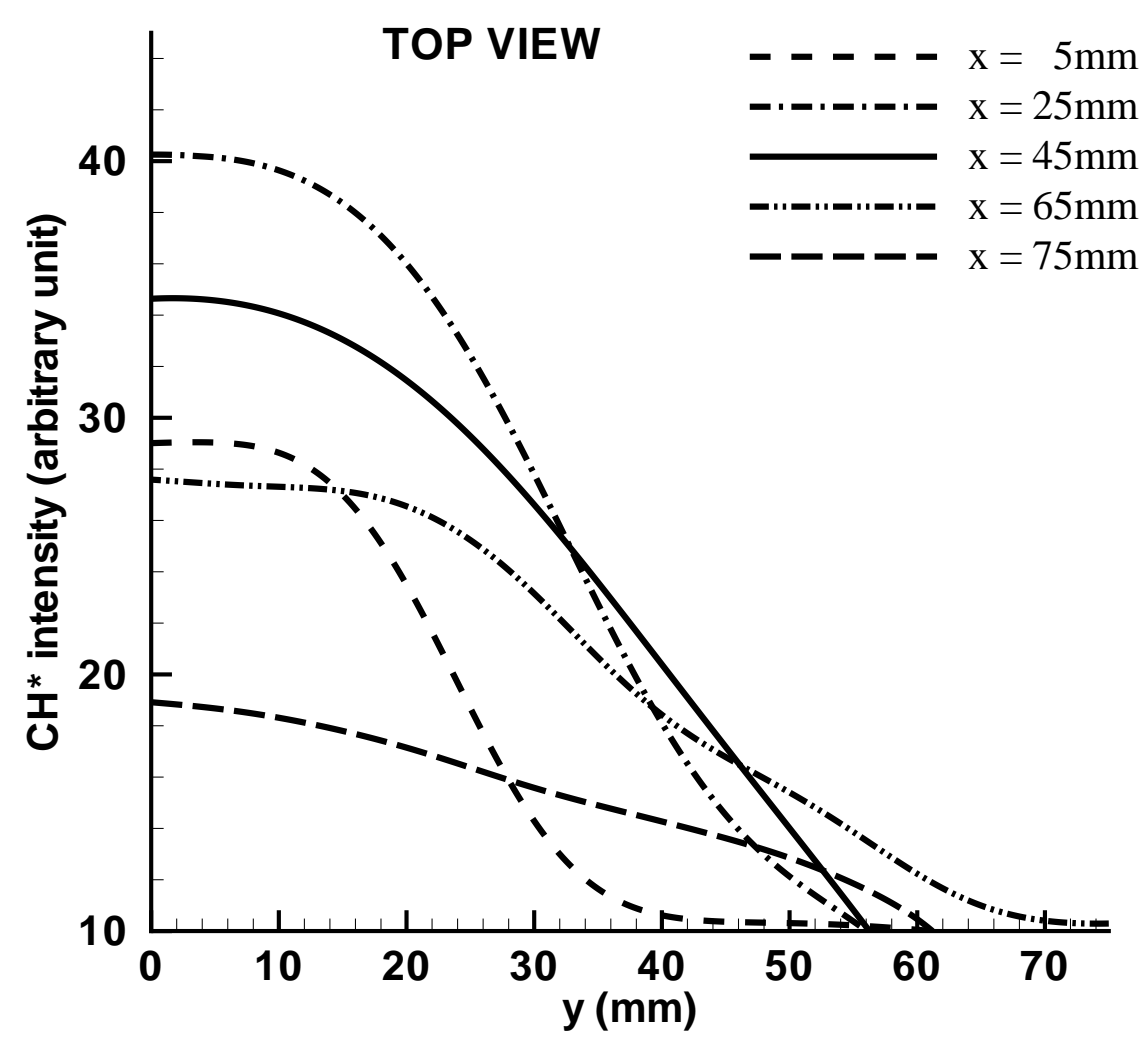

(a)

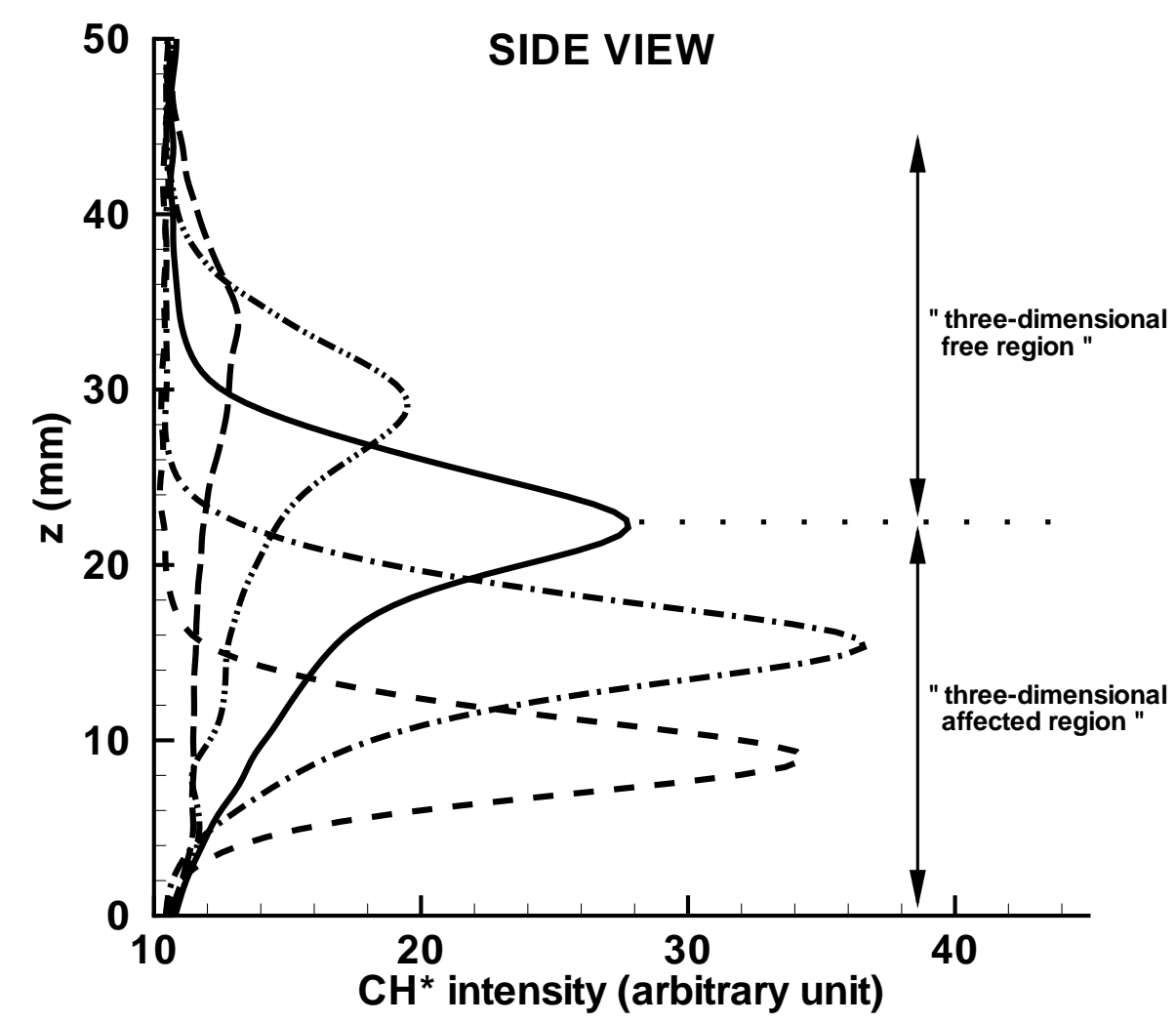

(b)

FIG. 6 - 


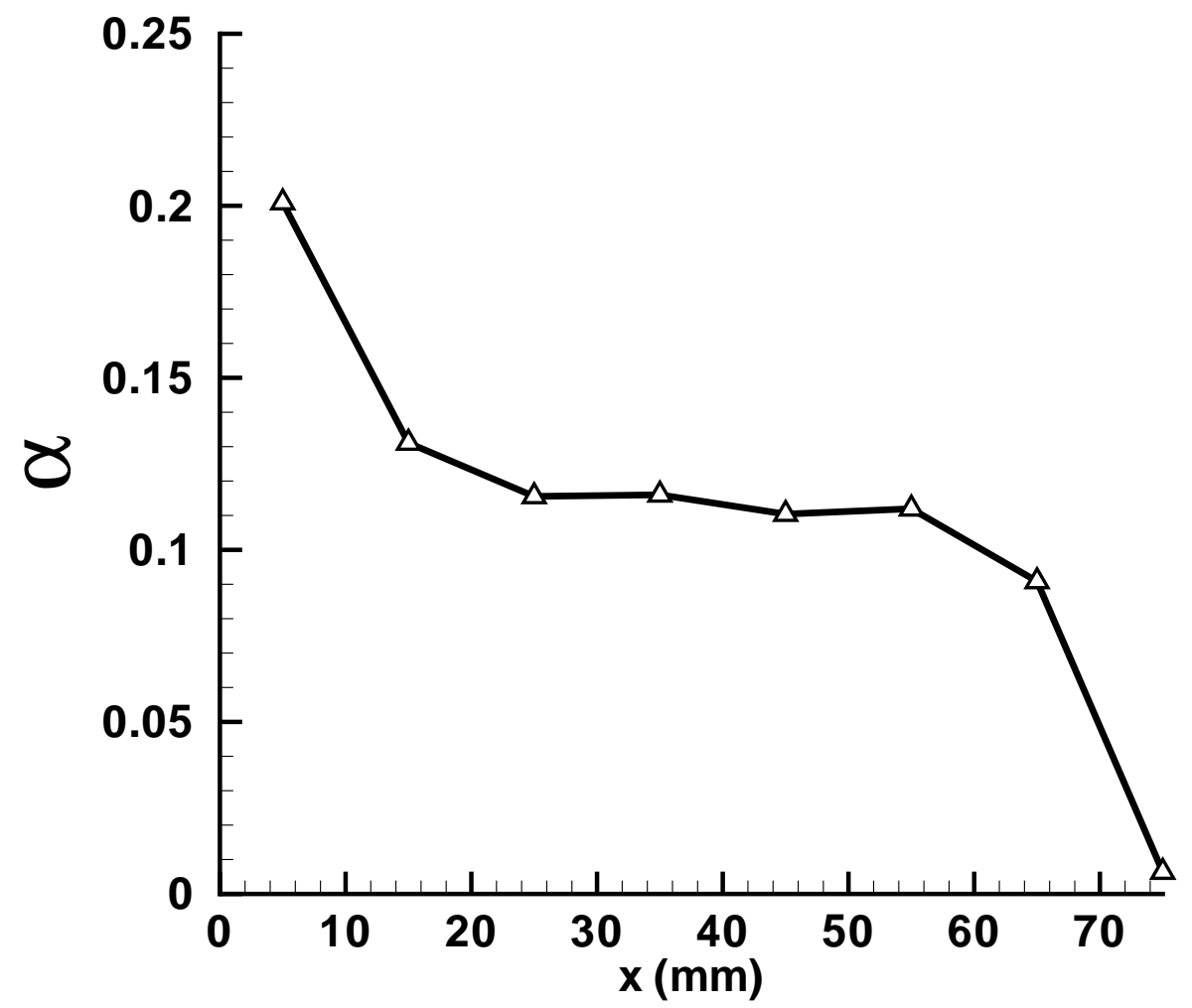

FIG. 7 - 


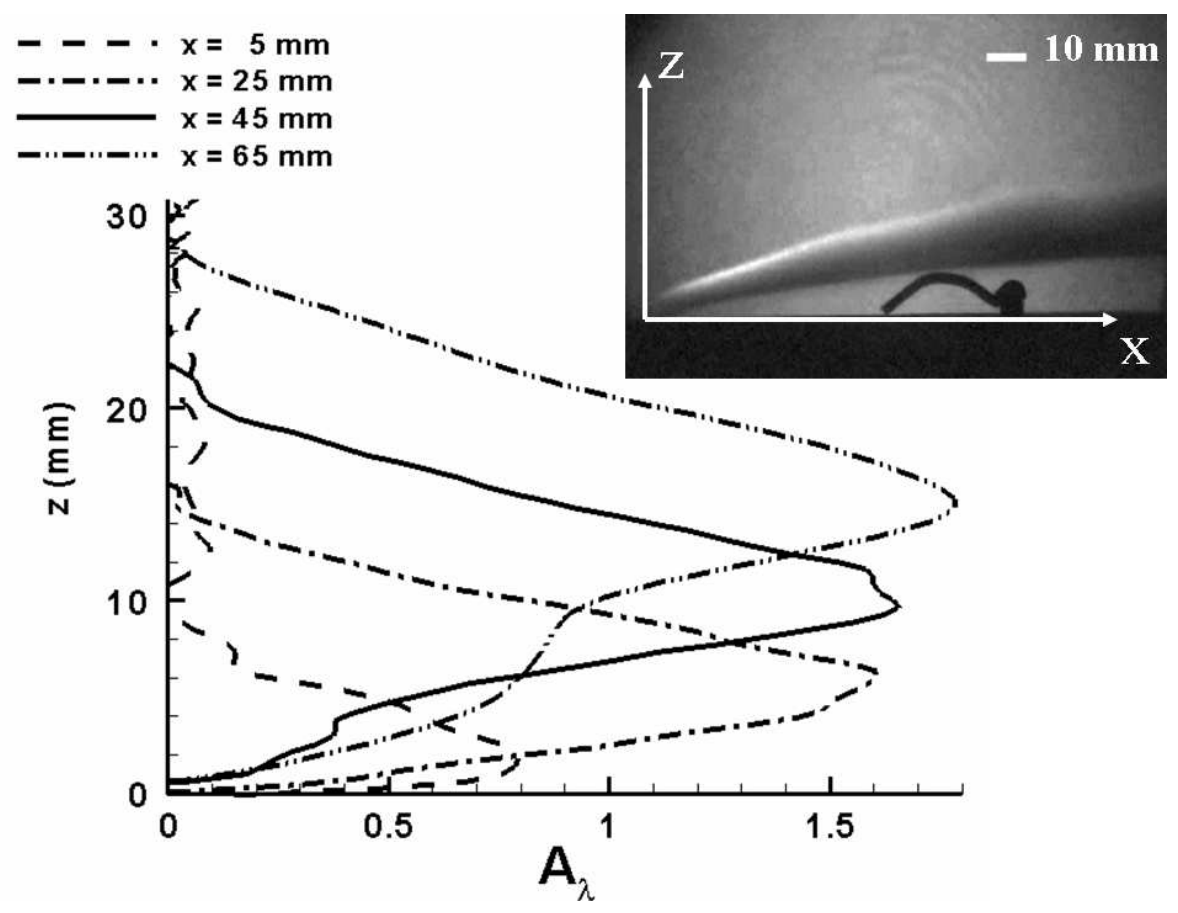

FIG. 8 


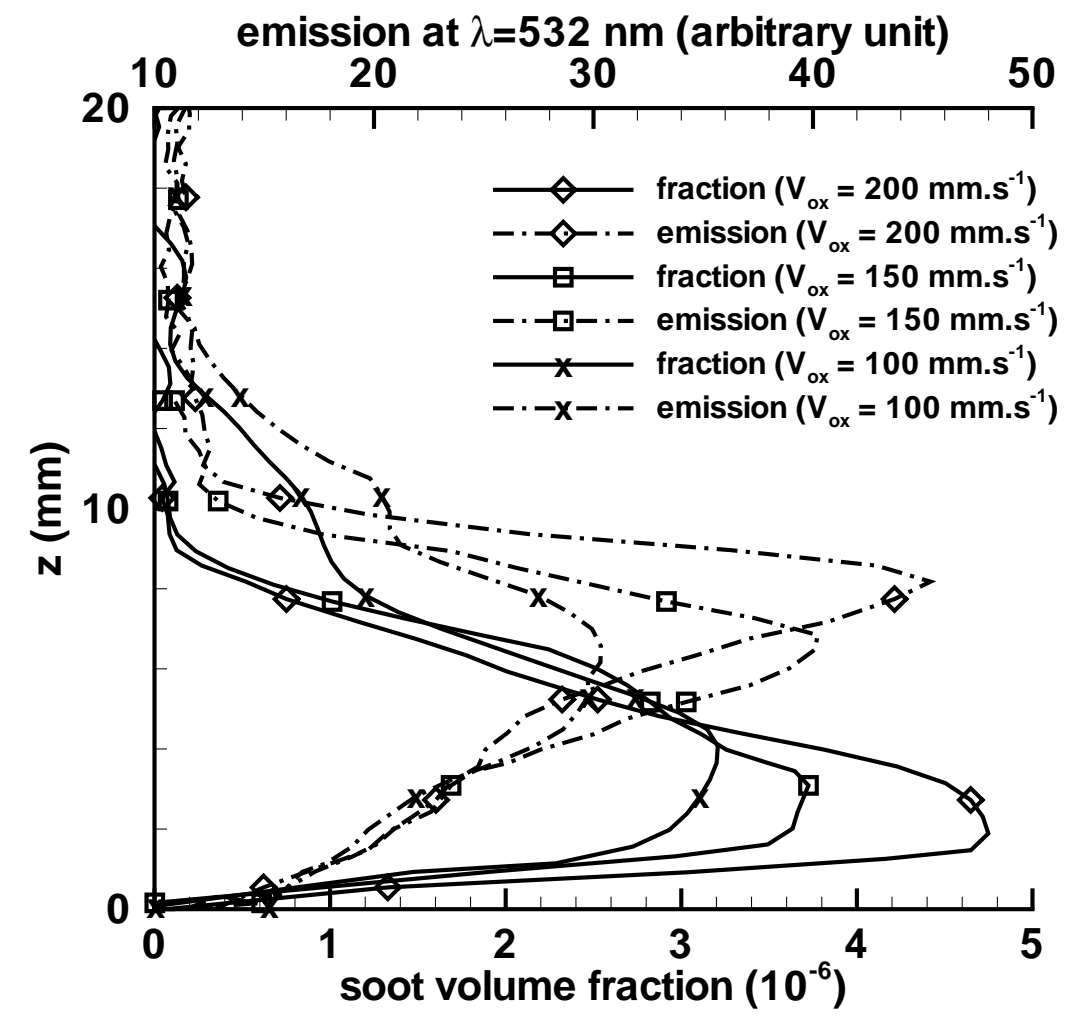

(a)

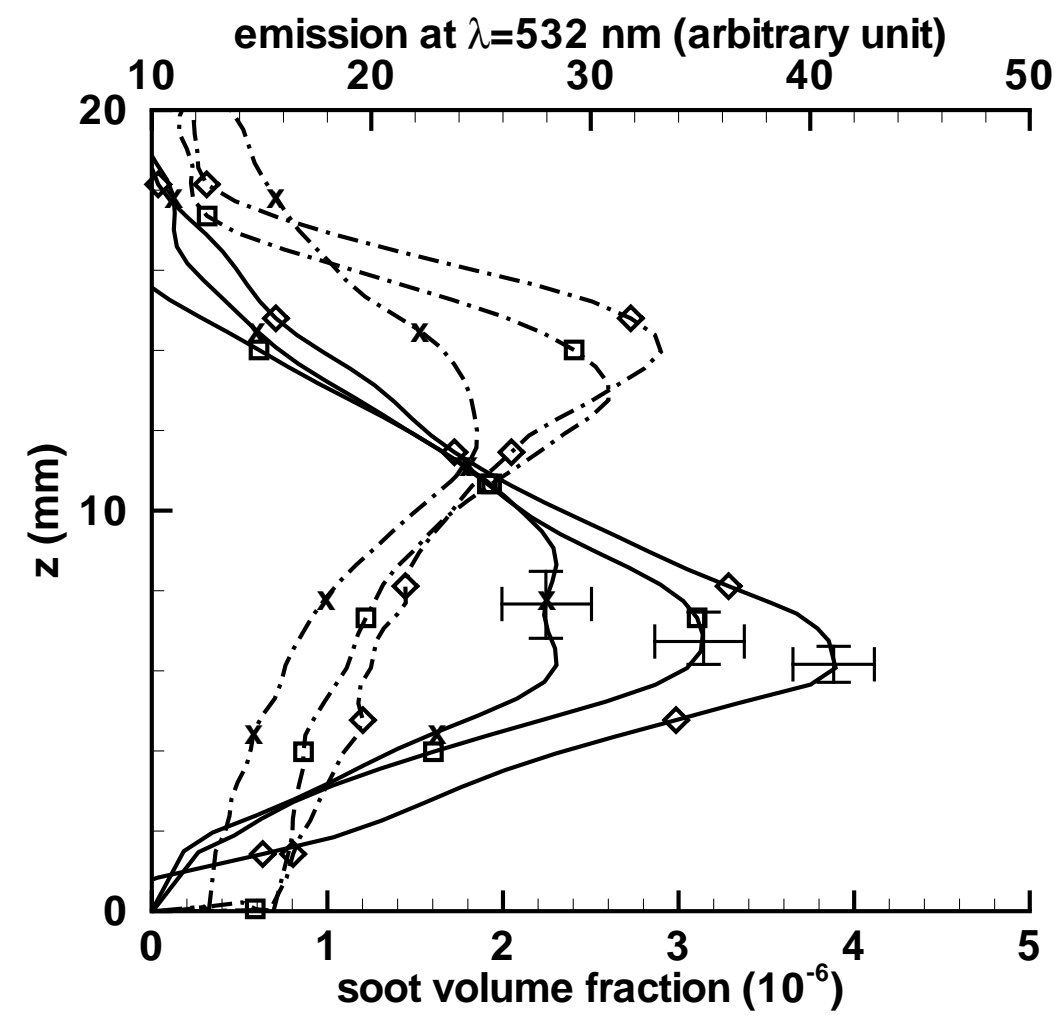

(b)

FIG. $9-$ 